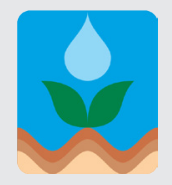

\author{
Revista Brasileira de Engenharia Agrícola e Ambiental \\ v.18, n.8, p.844-850, 2014 \\ Campina Grande, PB, UAEA/UFCG - http://www.agriambi.com.br \\ Protocolo 251.13 - 14/08/2013 • Aprovado em 28/03/2014
}

\title{
Vigor da cultivar BMX Potência RR de soja durante o beneficiamento e períodos de armazenamento
}

\author{
Adrieli N. K. Juvino' ${ }^{1}$, Osvaldo Resende 2 , Lílian M. Costa ${ }^{3} \&$ Juliana de F. Sales ${ }^{4}$
}

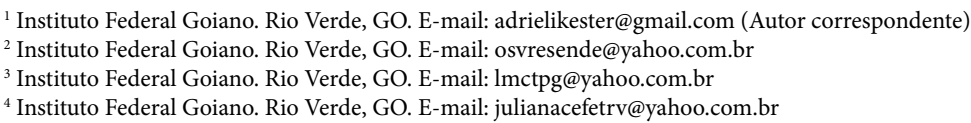

Palavras-chave:

danos mecânicos

condições de armazenamento

Glycine max (L.) Merrill

\begin{abstract}
R E S U M O
Objetivou-se, com este trabalho, avaliar o vigor das sementes de soja durante as etapas do beneficiamento e ao longo do armazenamento. O experimento foi desenvolvido no Instituto Federal Goiano, Câmpus Rio Verde, e na empresa Sementes Goiás. Utilizou-se o delineamento inteiramente casualizado, segundo o esquema fatorial triplo $6 \times 2 \times 4$ (seis etapas do beneficiamento, duas condições de armazenamento e quatro tempos de armazenamento) com três repetições. Foram utilizadas sementes de soja Glycine max (L.) Merrill, cultivar BMX Potência RR. As sementes foram avaliadas ao longo do armazenamento (0,3, 6 e 9 meses) quanto ao teor de água, teste de tetrazólio e emergência em areia. Os dados foram analisados por meio de análise de variância e regressão adotando-se o nível de 0,05 de significância. Concluiu-se que o beneficiamento das sementes de soja não afetou a qualidade fisiológica das sementes e a cultivar BMX Potência RR apresentou qualidade fisiológica superior pelo teste tetrazólio (acima de $80 \%$ ) apesar do vigor, germinação e emergência se apresentarem altos durante nove meses de armazenamento e o comprimento de raiz e de plantas jovens normais foi influenciado negativamente pelo tempo. Em câmara climatizada as sementes apresentam maior viabilidade dependendo do teor de água do produto.
\end{abstract}

Key words: mechanical damage storage conditions Glycine max (L.) Merrill

\section{Vigor of cultivar BMX Potência RR of soybean during processing and storage periods}

\begin{abstract}
A B S T R A C T
The aim of the present study was to evaluate the effect of soybean seeds during processing and storage. The experiment was conducted at Federal Institute of Goiás, Campus Rio Verde and the company Seeds Goiás. A completely randomized design was used according to the triple factorial scheme $6 \times 2 \times 4$ (six stages of processing, two storage conditions and four storage times), with three replications. Seeds of soybean (Glycine max L.) Merrill cultivar BMX Potência RR were used. The seeds were evaluated during storage (0, 3, 6 and 9 months) as to moisture content, tetrazolium and emergence in sand. Data were analysed by analysis of variance and regression, adopting the 0.05 level of significance. It was concluded that: the processing of soybean seeds did not affect the physiological quality of soybean seeds and cultivar BMX Potência RR showed higher physiological quality by tetrazolium test (above $80 \%$ ); although the vigor, germination and emergence remained high for nine months storage, the root length and number of normal young seedlings were negatively influenced by the weather. In climate chamber seeds showed higher viability depending on the moisture content of the product.
\end{abstract}

\section{INTRODUÇÃO}

O controle da qualidade assume importância fundamental para assegurar a obtenção de sementes de alta qualidade, quer seja na fase de campo ou nas etapas de beneficiamento e armazenamento (Kryzanowski et al., 2006). A qualidade das sementes reflete diretamente no desenvolvimento da cultura gerando plantas de elevado vigor, uniformidade de população e ausência de doenças transmitidas via semente (Silva et al., 2010) fatores que podem influenciar diretamente no rendimento de grãos (Scheeren et al., 2010; Kolchinski et al., 2005).
O beneficiamento é componente fundamental em qualquer programa de produção de sementes e tem, como objetivo, aprimorar a qualidade das sementes dando condições de ser utilizado pelos produtores e de atender aos padrões mínimos de comercialização que são pré-estabelecidos pelas normas legais vigentes (Baudet et al., 1999). No beneficiamento as sementes passam por várias etapas; entretanto, nem todos os lotes seguem uma mesma sequência de forma que as operações neste processo são realizadas em função da espécie, da cultivar e das características físicas e das impurezas presentes (Ferreira \& Sá, 2010). Segundo Marcos Filho (2013) o embrião da semente de soja é protegido por um tegumento relativamente frágil, o 
eixo embrionário é superficial e suscetível a injúrias mecânicas provocadas por outros agentes externos demonstrando que a semente pode sofrer injúrias mecânicas durante as etapas do beneficiamento.

O armazenamento é uma prática fundamental para manter a qualidade fisiológica da semente e garantir a manutenção de vigor e viabilidade no período entre a colheita e a semeadura (Azevedo et al., 2003). Apesar disto, o ambiente de armazenamento influencia diretamente na manutenção desta qualidade. De acordo com Marcos Filho (2005) para uma conservação melhor das sementes ortodoxas, como as de soja, o ambiente com umidade relativa e temperatura mais baixas tem-se mostrado adequado já que essas condições permitem manutenção de baixo nível de atividade de reações químicas e preservação do poder germinativo e do vigor das sementes.

A umidade relativa e a temperatura são os principais fatores que afetam a qualidade das sementes no armazenamento e sua manutenção nas condições ideais refletirá na viabilidade do lote evitando os descartes por reduções de germinação abaixo dos padrões de sementes para cada espécie (Macedo et al., 1998). Ante o exposto, o objetivo deste trabalho foi avaliar a influência do beneficiamento e do armazenamento no vigor de sementes de soja utilizando o teste de tetrazólio e emergência em areia.

\section{Material e Métodos}

As sementes utilizadas no ensaio foram provenientes de campos de produção dos municípios de Rio Verde e Montividiu, no estado de Goiás; cultivadas na safra 2011/2012 a cultivar utilizada foi a BMX Potência RR. As sementes foram colhidas mecanicamente (abril de 2012) e transportadas a granel para a Unidade de Beneficiamento de Sementes (UBS) da empresa Sementes Goiás, no município de Rio Verde, GO.

Inicialmente, as sementes passaram pela recepção onde foram pesadas, amostradas e submetidas à secagem artificial em secadores estacionários até o teor de água final em torno de $11 \%$ base úmida (b.u.); após a secagem as sementes foram encaminhadas para o beneficiamento; durante essas etapas as sementes foram transportadas através de correias transportadoras, elevadores de corrente e tubulações (Figura 1). Foram retiradas amostras durante tais etapas constituindo seis tratamentos: 1 - Pós-limpeza, amostra retirada após a passagem pela máquina de pré-limpeza (B1); 2 - Amostra retirada na entrada do peneirão (B2); 3 - Saída, amostra retirada na saída do peneirão com diâmetro 6,5 mm (B3); 4 - Mesa densimétrica, retirada na entrada da mesa densimétrica (B4); 5 - Pós mesa densimétrica, retirada após a passagem pela mesa densimétrica (B5) 6 - Ensaque, amostra retirada após o beneficiamento, pronta para ser ensacada (B6).

Depois de homogeneizadas as amostras foram acondicionadas em embalagens individuais de papelão com capacidade de $1,0 \mathrm{~kg}$ e mantidas em câmara climatizada - CC $\left(18 \pm 2{ }^{\circ} \mathrm{C}\right)$ e em ambiente natural - $\mathrm{AN}\left(25 \pm 2{ }^{\circ} \mathrm{C}\right)$ sendo a temperatura e a umidade relativa desses ambientes monitoradas por meio de um registrador digital (Datalogger Log Box RHT-LCD) como ilustrado na Figura 2.

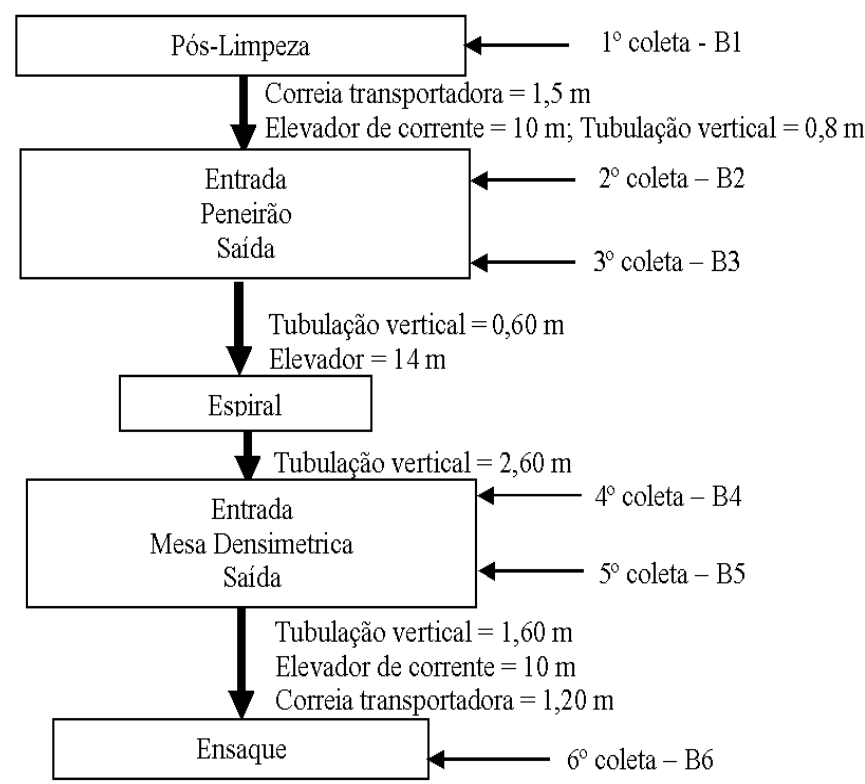

Figura 1. Fluxograma ilustrativo das etapas de beneficiamento de sementes de soja na Unidade de Beneficiamento de Sementes Goiás em Rio Verde, GO
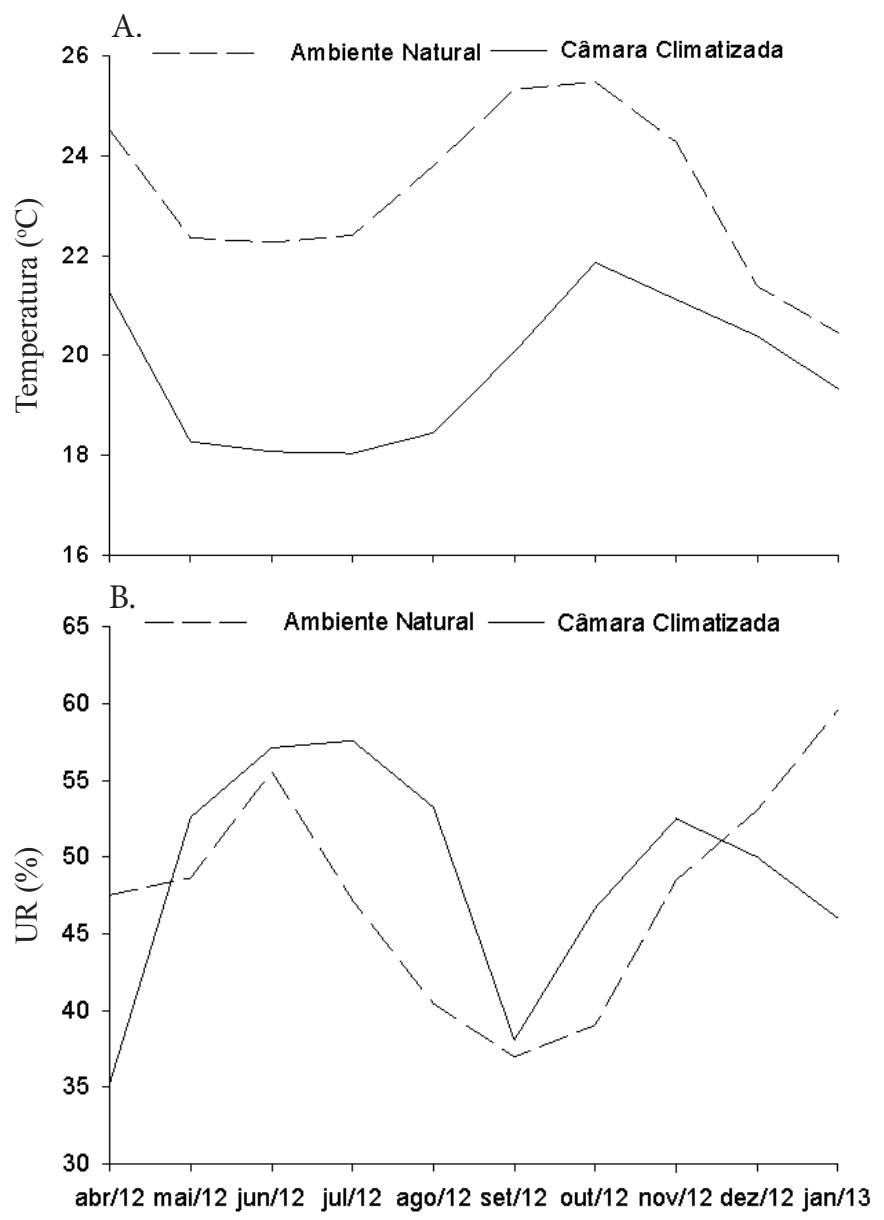

Tempo de armazenamento (meses)

Figura 2. Temperaturas médias mensais do ambiente natural e da câmara climatizada (A). Umidades Relativas (UR) médias mensais do ambiente natural e da câmara climatizada (B) ao longo do tempo de armazenamento em sementes de soja 
$\mathrm{O}$ armazenamento foi realizado entre os meses de abril de 2012 até janeiro do ano de 2013. As avaliações foram realizadas ao longo do armazenamento, aos 0, 3, 6 e 9 meses, sendo que o teor de água foi determinado por meio do método padrão da estufa a $105 \pm 3^{\circ} \mathrm{C}$ por $24 \mathrm{~h}$ (Brasil, 2009) e o teste de tetrazólio foi conduzido em duas subamostras de 50 sementes para cada tratamento, pré-condicionadas em papel de germinação tipo germitest, umedecido e mantido nestas condições por $16 \mathrm{~h}$ a 25 ${ }^{\circ} \mathrm{C}$; posteriormente, as sementes foram transferidas para copos plásticos (capacidade $50 \mathrm{~mL}$ ) com solução de trifenil cloreto de tetrazólio na concentração de $0,075 \%$ e mantidas em câmara escura por até $3 \mathrm{~h}, \mathrm{a} 40^{\circ} \mathrm{C}$. Decorrido este período as sementes foram lavadas em água corrente e em seguida avaliadas de forma individual com corte longitudinal ao eixo embrionário (França Neto et al., 1999). Os resultados foram expressos em três categorias distintas: vigor (nível 1-3); germinação (nível 1-5) e danos mecânicos (nível 6-8) representados em porcentagem.

$\mathrm{Na}$ avaliação de emergência (Nakagawa, 1999) foram utilizadas quatro repetições de 25 sementes em cada tratamento semeadas em canteiro de areia em casa de vegetação com nebulização intermitente três vezes ao dia, a uma profundidade de $2 \mathrm{~cm}$. Na emergência foram consideradas emergidas as plântulas que apresentaram os cotilédones $1 \mathrm{~cm}$ acima do substrato com contagem a partir do $1^{\circ}$ até o $14^{\circ}$ dia após a semeadura (DAS) quando foram avaliados a emergência total EM (ao 14 DAS) e o Índice de velocidade de emergência (IVE) calculado segundo Maguire (1962).

Foram avaliados também, no $14^{\circ}$ DAS, conjuntamente com o teste de emergência, a porcentagem de plantas jovens normais (PJN), o comprimento do sistema radicular (CR) de dez plantas jovens normais escolhidas aleatoriamente e a medição foi realizada no início da raiz até o final de sua extensão com auxílio de uma régua graduada.

O experimento foi montado em delineamento inteiramente casualizado em um esquema fatorial triplo $6 \times 2 \times 4$ (seis etapas do beneficiamento, duas condições de armazenamento e 4 tempos de armazenamento) com três repetições. Os dados foram analisados por meio de análise de variância e regressão; os modelos foram selecionados com base na significância da equação, pelo teste $F$, na significância dos coeficientes de regressão utilizando-se o teste " $\mathrm{t}$ " e se adotando o nível de 5\% de significância no coeficiente de determinação $\left(\mathrm{R}^{2}\right)$.

\section{Resultados e Discussão}

Na Tabela 1 encontra-se o resumo da análise de variância. Nota-se interação entre etapas do beneficiamento (EB), o armazenamento (Arm) e o tempo (Tem) somente para o comprimento de raiz (CR) a 0,05 de probabilidade pelo teste F. Para plantas jovens normais (PJN), emergência total (EM) ocorreu interação entre EB e Tem a 0,01 assim como entre Arm e Tem a 0,05 de probabilidade; para índice de velocidade de emergência (IVE) somente o Tem foi significativo a 0,05 enquanto para danos mecânicos DM houve diferença significativa entre EB e Tem; já para a variável vigor $(V)$ a interação a 0,01 se deu entre EB e Arm e a 0,05 entre EB e Tem; enfim, para o teor de água (TA) houve interação a $1 \%$ entre as fontes de variação Arm e Tem.

Na Figura 3 são apresentados os valores médios de teor de água das sementes de soja durante os meses avaliados no armazenamento. Os dados mostram que a partir do terceiro mês de armazenamento houve diferença entre os ambientes em que as sementes ficaram armazenadas; no terceiro mês de armazenamento (julho de 2012) as sementes perderam maior quantidade de água quando armazenadas em câmara climatizada (CC) comparadas com aquelas armazenadas em ambiente natural (AN); esta redução do teor de água está

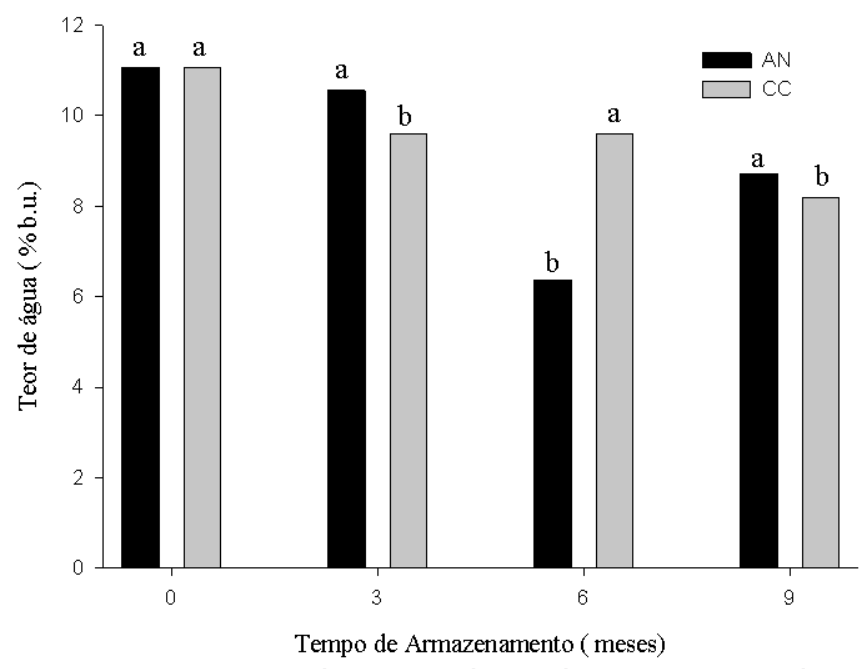

Figura 3. Teor de água (b.u) das sementes de soja armazenadas em ambiente natural e câmara climatizada ao longo do tempo de armazenamento

Tabela 1. Resumo da análise de variância para \% de emergência total (EM), danos mecânicos (DM) e vigor (V) pelo teste de tetrazólio, plantas jovens normais (PJN) índice de velocidade de emergência (IVE), comprimento de raiz (CR) e teor de água (TA)

\begin{tabular}{|c|c|c|c|c|c|c|c|c|}
\hline \multirow{2}{*}{ FV } & \multirow{2}{*}{ GL } & \multicolumn{7}{|c|}{ Quadrados médios } \\
\hline & & EM & DM & V & PJN & IVE & CR & TA \\
\hline $\mathrm{EB}$ & 5 & $46,311^{\mathrm{NS}}$ & $2,494^{\mathrm{NS}}$ & $17,023^{\mathrm{NS}}$ & $49,079^{\text {NS }}$ & $1,493^{\mathrm{NS}}$ & $2,141^{\star}$ & $0,566^{\mathrm{NS}}$ \\
\hline Arm & 1 & $113,777^{\star}$ & $4,694^{\mathrm{NS}}$ & $0,340^{\mathrm{NS}}$ & $91,840^{\text {NS }}$ & $3,004^{\mathrm{NS}}$ & $8,371^{\star *}$ & $6,860^{\star \star}$ \\
\hline Tem & 3 & $1084,56^{* *}$ & $3,462^{\mathrm{NS}}$ & $21,599^{\mathrm{NS}}$ & $1368,581^{* *}$ & $18,667^{* *}$ & $42,311^{* *}$ & $73,265^{* *}$ \\
\hline EB X Arm & 5 & $32,06^{\mathrm{NS}}$ & $0,711^{\mathrm{NS}}$ & $31,623^{* *}$ & $24,356^{\mathrm{NS}}$ & $0,724^{\mathrm{NS}}$ & $0,837^{\mathrm{NS}}$ & $0,3100^{\mathrm{NS}}$ \\
\hline EB X Tem & 15 & $86,825^{\star \star}$ & $2,735^{* *}$ & $13,527^{\star}$ & $133,142^{\star \star}$ & $0,874^{\mathrm{NS}}$ & $1,393^{\mathrm{NS}}$ & $0,384^{\mathrm{NS}}$ \\
\hline Arm X Tem & 3 & $84,611^{*}$ & $1,157^{\mathrm{NS}}$ & $0,525^{\mathrm{NS}}$ & $80,747^{*}$ & $1,123^{\mathrm{NS}}$ & $1,717^{\mathrm{NS}}$ & $32,753^{\star \star}$ \\
\hline EB X Arm X Tem & 15 & $42,516^{\mathrm{NS}}$ & $1,907^{\mathrm{NS}}$ & $11,342^{\mathrm{NS}}$ & $48,197^{\mathrm{NS}}$ & $1,372^{\mathrm{NS}}$ & $1,772^{*}$ & $0,216^{\mathrm{NS}}$ \\
\hline CV (\%) & & 5,41 & 10,17 & 3,0 & 6,56 & 18,4 & 6,97 & 6,22 \\
\hline
\end{tabular}

**Significativo a nivel de 0,01 ; *Significativo a nível de 0,05 e NSNão significativa pelo teste de $\mathrm{F}$ 
relacionada com a permeabilidade da embalagem em que as sementes foram armazenadas haja vista que estas permitem troca de vapor d'água com o ambiente; esses dados corroboram com Carvalho \& Nakagawa (2012) que relataram a influência da temperatura e da umidade relativa no teor de água do produto, devido à sua higroscopicidade.

No sexto mês de armazenamento (outubro de 2012) o comportamento do teor de água das sementes foi contrário àquele encontrado no terceiro mês em que as sementes armazenadas em AN apresentaram teores muito abaixo (6,3\% b.u.) daquelas armazenadas em CC (9,6\% b.u.). É provável que esta diferença de $3,3 \%$ possa ser atribuída às condições climáticas (temperatura e umidade relativa) encontradas no sexto mês para ambas as condições de armazenamento, conforme ilustrado na Figura 2. O maior aumento da temperatura e queda da UR ocorreu no AN durante os nove meses avaliados; de acordo com Carvalho \& Nakagawa (2012) mudanças na temperatura e na umidade relativa do ar provocam ajustes constantes no teor de água das sementes armazenadas em embalagens permeáveis ao vapor de água.

No nono mês de armazenamento (janeiro de 2012) constatou-se diferença entre as condições de armazenamento com aumento do teor de água para $\mathrm{AN}$ e redução para CC, o que também permite afirmar que esta diferença se deve às condições climáticas dos ambientes de armazenamento.

Segundo Kryzanowski et al. (2006) o teste tetrazólio (TZ), permite conhecer a viabilidade e o vigor da semente sendo possível diagnosticar os principais problemas que podem afetar sua qualidade, tais como danos mecânicos, deterioração por umidade e dano por percevejo, que são os problemas que mais comumente afetam a qualidade fisiológica da semente de soja. Este teste tem-se destacado, sobretudo para a soja devido à sua rapidez, precisão e também pelo grande número de informações fornecidas. Além de avaliar a viabilidade e o vigor dos lotes, fornece o diagnóstico das possíveis causas da redução de sua qualidade.

Os danos mecânicos avaliados pelo teste de tetrazólio (TZ 6-8) contidos na Tabela 2 demonstram que houve diferença entre as etapas do beneficiamento somente no mês inicial de avaliação quando B2 (entrada do peneirão) apresentou os maiores valores de danos mecânicos $(4,3 \%)$ diferindo somente de B1, B3 e B4. Oliveira et al. (1999) observaram, estudando a ocorrência de danos mecânicos pelo teste tetrazólio (TZ 6-8) durante o beneficiamento em sementes de soja cultivar Dourados, que não houve diferença entre os primeiros pontos de amostragem comparados aos últimos pontos e atribuíram este resultado possivelmente à remoção das sementes danificadas, por meio do separador em espiral e pela mesa densimétrica diminuindo a porcentagem de sementes inviáveis no lote, ao final do beneficiamento.

De maneira geral, infere-se que o lote de sementes avaliadas (cultivar BMX Potência RR) apresentou baixa porcentagem de danos mecânicos (nível 6-8) cujos maiores valores foram observados no tempo inicial e a partir do terceiro mês de avaliação, em que todos os tratamentos apresentaram valores inferiores a 3,0\%, demonstrando a boa qualidade do lote.
Isto pode ser atribuído possivelmente ao teor de água do produto que desde o início das avaliações apresentou valores inferiores a $11,7 \%$ b.u., abaixo, portanto, do recomendado para armazenamento ( $12 \%$ b.u.) o que pode ter proporcionado resistência mecânica às sementes.

Tabela 2. Danos mecânicos (nível 6-8) das sementes de soja em função das coletas e do tempo de armazenamento determinados pelo teste de tetrazólio

\begin{tabular}{ccccc}
\hline Etapas do & \multicolumn{4}{c}{ Tempo de armazenamento (meses) } \\
\cline { 2 - 5 } beneficiamento & $\mathbf{0}$ & $\mathbf{3}$ & $\mathbf{6}$ & $\mathbf{9}$ \\
$\mathrm{B} 1$ & $2,0 \mathrm{~b}$ & $3,0 \mathrm{a}$ & $2,3 \mathrm{a}$ & $1,8 \mathrm{a}$ \\
B2 & $4,3 \mathrm{a}$ & $2,8 \mathrm{a}$ & $1,8 \mathrm{a}$ & $1,1 \mathrm{a}$ \\
B3 & $2,0 \mathrm{~b}$ & $2,5 \mathrm{a}$ & $2,5 \mathrm{a}$ & $2,1 \mathrm{a}$ \\
B4 & $1,6 \mathrm{~b}$ & $2,5 \mathrm{a}$ & $1,6 \mathrm{a}$ & $2,3 \mathrm{a}$ \\
B5 & $3,6 \mathrm{ab}$ & $2,5 \mathrm{a}$ & $2,5 \mathrm{a}$ & $3,1 \mathrm{a}$ \\
B6 & $2,6 \mathrm{ab}$ & $2,1 \mathrm{a}$ & $1,8 \mathrm{a}$ & $2,1 \mathrm{a}$ \\
\hline
\end{tabular}

Médias seguidas de letra minúscula entre as colunas não diferem entre si pelo teste de Tukey a 0,05 de significância. B1 - Pós-limpeza; B2 - Entrada do peneirão; B3 - Saída do peneirão; B4 - Entrada da mesa densimétrica; B5 - Saída mesa densimétrica; B6 - Ensaque

Segundo Tunes et al. (2011) a qualidade das sementes pode ser caracterizada pela germinação e pelo vigor, o qual pode ser definido como a somatória de atributos que conferem, à semente, o potencial de germinar, emergir e resultar rapidamente em plântulas normais sob ampla diversidade de condições ambientais. $\mathrm{O}$ vigor das sementes de armazenamento pelo teste de tetrazólio foi apresentado na Tabela 3. Como se observa, os dados diferiram quanto aos ambientes armazenados somente para as etapas de beneficiamento $\mathrm{B} 2 \mathrm{e} \mathrm{B} 3$ sendo que no primeiro o vigor foi superior para o armazenamento em CC; já para o último, a condição de armazenamento $\mathrm{AN}$ apresentou valor superior; para as demais etapas não houve diferença entre as condições de armazenamento.

Com relação às etapas do beneficiamento, observou-se que B3 e B4 apresentaram valores superiores diferindo de B2 para a condição NA; para a condição de armazenamento CC, apenas B2 diferiu de B5. Lopes et al. (2011) observaram, estudando efeitos dos danos mecânicos e fisiológicos na colheita e beneficiamento de sementes de soja pelo teste de vigor (tetrazólio) que ao final do processo de beneficiamento (ensaque) esses valores se apresentavam também acima de $80 \%$.

Apesar das diferenças pode-se inferir que todos os valores encontrados para o vigor estão acima daqueles recomendados para a comercialização de sementes de soja no Brasil, que variam atualmente entre 80 a $85 \%$ (Brasil, 2009) demonstrando a boa qualidade fisiológica da cultivar em estudo. Silva et

Tabela 3. Vigor (nível 1-3) determinado pelo teste de tetrazólio (\%) das sementes de soja, em função das condições de armazenamento e das etapas do beneficiamento

\begin{tabular}{|c|c|c|c|c|c|c|}
\hline \multirow{2}{*}{$\begin{array}{l}\text { Condições de } \\
\text { armazenamento }\end{array}$} & \multicolumn{6}{|c|}{ Etapas do beneficiamento } \\
\hline & B1 & B2 & B3 & B4 & B5 & B6 \\
\hline AN & 89,5 & 1 & 1,5 & $92,0 \mathrm{a}$ & $88,8 a$ & $88,9 \mathrm{aAB}$ \\
\hline CC & $89,9 \mathrm{a}$ & 7 &, 7 & $90,3 \mathrm{a}$ & $88,2 \mathrm{aB}$ & $90,5 \mathrm{aA}$ \\
\hline
\end{tabular}

Médias seguidas de letra minúscula entre as colunas e maiúsculas entre as linhas não diferem entre si pelo teste de Tukey a 0,05 de significância. B1 - Pós-limpeza; B2 - Entrada do peneirão; B3 - Saída do peneirão; B4 - Entrada da mesa densimétrica; B5 - Saída mesa densimétrica; B6 - Ensaque; AN - ambiente natural; CC - câmara climatizada 
al. (2011) observaram comportamento semelhante em um estudo realizado com quatro cultivares de soja (Vencedora, Emgopa-313, Luziânia e Valiosa) e concluíram que somente a cultivar vencedora apresentou redução do vigor (abaixo de 70\%) quando submetida às etapas do beneficiamento $\left(1^{\circ}\right.$ - secador; $2^{\circ}$ - elevadores de caneca número $1 ; 3^{\circ}$ - elevadores de caneca número 2; $4^{\circ}$ - elevadores de caneca número 3 e $5^{\circ}$ - espiral), para as demais cultivares o vigor permaneceu acima de $80 \%$.

A qualidade fisiológica da semente é fator de extrema importância para que se obtenha a produtividade esperada, e o armazenamento é prática fundamental para o controle da qualidade fisiológica, sendo um processo por meio do qual se pode preservar a viabilidade das sementes (Azevedo et al., 2003). Na Figura 4 estão apresentados os valores médios de emergência total (\%) para as condições de AN e CC ao longo do tempo de armazenamento. Observa-se que a emergência foi diminuindo ao longo dos meses com comportamento linear decrescente. Em AN os valores estimados de emergência foram de 97,$16 ; 93,08 ; 88,0$ e $84,97 \%$ para os meses $0,3,6$ e 9 , respectivamente. Quanto à condição de armazenamento em CC os valores encontrados foram 97,51; 94,27; 91,03 e $87,79 \%$, para os meses $0,3,6$ e 9, respectivamente. Para a condição de armazenamento AN ocorreu um decréscimo mais acentuado principalmente para o sexto e o nono meses, comparados ao CC; no sexto mês esta diferença foi de 3,03\%; já para o nono mês foi de $2,87 \%$. Isto pode ser atribuído, possivelmente, às condições climáticas do NA (temperatura e UR) apresentadas no sexto mês de avaliação prejudicando, desta forma, a emergência das sementes no referido mês, assim como a preservação da qualidade nos meses que se sucederam. Segundo Carvalho \& Nakagawa (2012) temperaturas elevadas influenciam consideravelmente na preservação da qualidade da semente armazenada por influenciar as atividades biológicas e acelerar as atividades respiratórias da semente e dos microrganismos a ela associados. Assim, a maioria das espécies terá suas sementes tanto melhor conservadas quanto mais baixa for a temperatura do ar no armazenamento.

Segundo Dan et al. (2011) o índice de velocidade de emergência (IVE) é um fator preponderante para o rápido estabelecimento das plântulas em condições de campo. As plântulas com maior IVE possuem maior desempenho e, em contrapartida, maior capacidade de resistir a estresse que por ventura possa interferir no crescimento e no desenvolvimento da planta. Na Figura 4 estão apresentados os valores médios de IVE para as sementes de soja ao longo do armazenamento. Observa-se um decréscimo linear ao longo do tempo, de 5,44 no início para 3,84 ao final do armazenamento. Segundo Salinas et al. (2001) a qualidade das sementes diminui com o transcorrer do tempo e a taxa de deterioração depende das condições ambientais durante o armazenamento e do tempo em que essas permanecem armazenadas. Um resultado semelhante foi observado na emergência com redução dos valores ao longo do período em que as sementes ficaram armazenadas.

As equações de regressão e os coeficientes de determinação resultantes das análises de regressão para comprimento de raiz (CR) estão apresentados na Figura 5. Vanzolini et al. (2007)
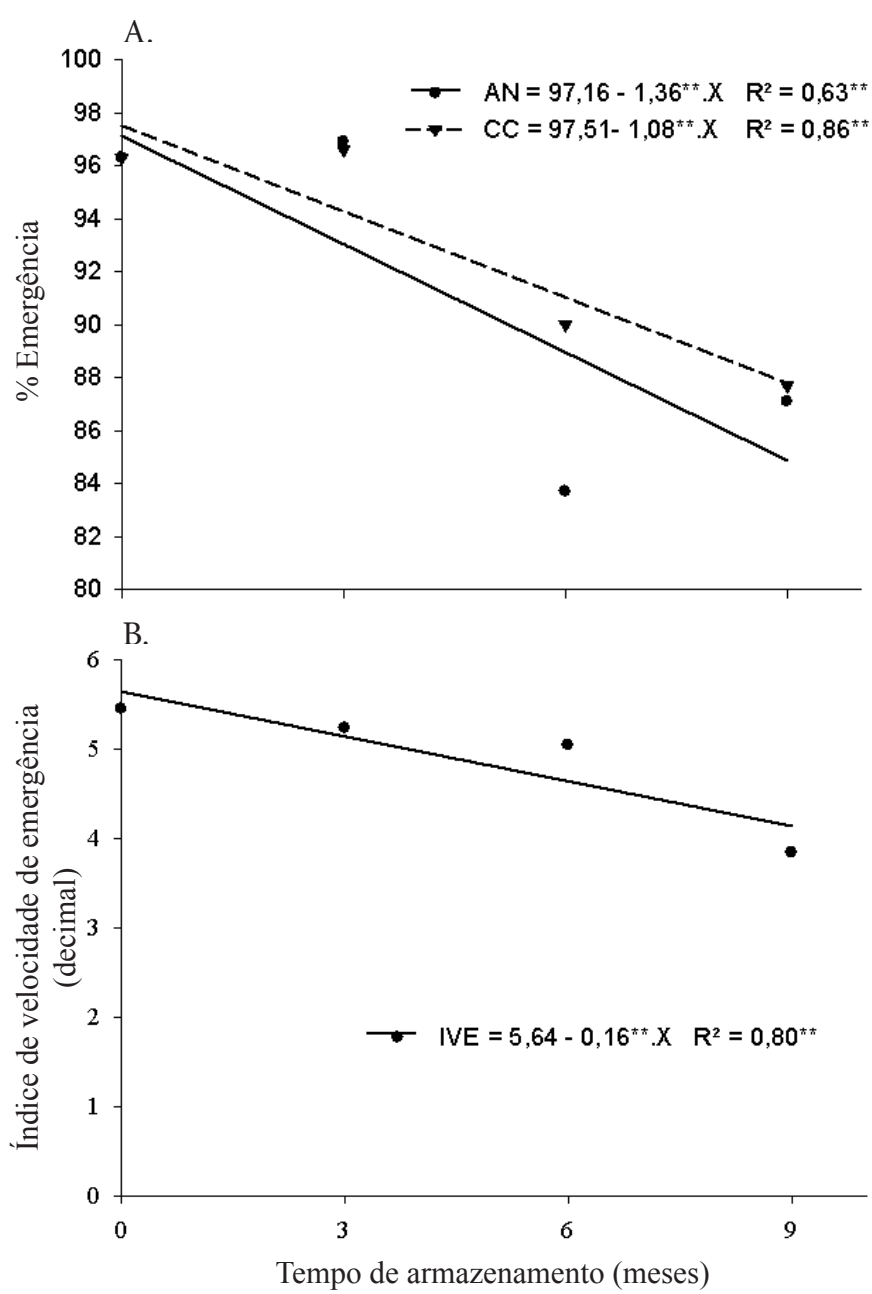

Valores experimentais e estimados do Índice de velocidade de emergência (decimal) das sementes de soja ao longo do tempo de armazenamento (B)

Figura 4. Valores experimentais e estimados de emergência total (\%) de plantas jovens emergidas das sementes de soja ao longo do armazenamento nos ambiente natural - AN e câmara climatizada CC (A)

citam que o comprimento da raiz de soja é uma variável sensível para diferenciar lotes, apresentando correlação positiva com a emergência das plântulas de soja em campo. Segundo Marcos Filho (2013) os testes baseados no desempenho de plântulas, como comprimento da raiz primária e da parte aérea, permitem avaliar o vigor de sementes de soja.

Os resultados demonstram que em todas as etapas do beneficiamento para ambas as condições de armazenamento houve decréscimo nesta variável ao longo do tempo, com exceção dos tratamentos $\mathrm{B} 3 \mathrm{e} \mathrm{B} 6$, que praticamente mantiveram suas médias ao longo do armazenamento. Observa-se que, de maneira geral, as médias ficaram próximas umas das outras, mas é possível perceber que o decréscimo foi mais acentuado para a condição de armazenamento em AN (Figura 5A). Dan et al. (2010) encontraram, estudando o armazenamento de sementes de soja, decréscimo do comprimento da raiz durante os 45 dias de avaliação. Bezerra et al. (2004) também perceberam decréscimo no comprimento de raiz em sementes de Moringa oleifea (oleaginosa) com o decorrer do tempo 


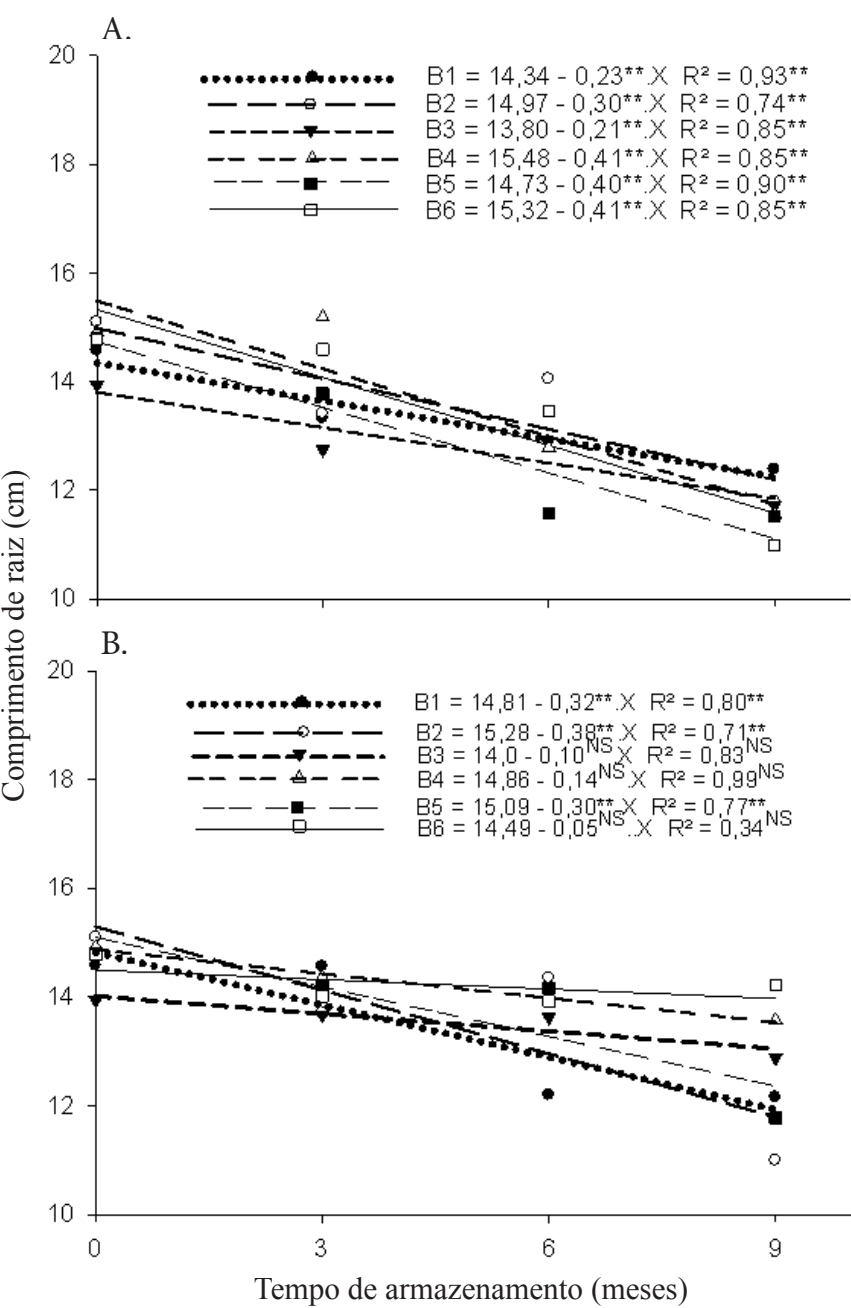

Figura 5. Valores experimentais e estimados de comprimento de raiz $(\mathrm{cm})$ de plantas jovens normais emergidas das sementes de soja em função das etapas do beneficiamento e do tempo de armazenamento em condição de ambiente natural (A) e câmara climatizada (B)

de armazenamento; esta diminuição foi mais acentuada nas sementes armazenadas sob condições não controladas do que em câmara fria $\left(10^{\circ} \mathrm{C}\right.$ e $55 \%$ de umidade relativa - UR).

De acordo com Nakagawa et al. (1999) os testes que avaliam o crescimento de plântulas são os mais sensíveis para a determinação do vigor de sementes de muitas espécies. Na Figura 6 estão apresentados os dados de plantas jovens normais (PJN) em função dos ambientes de armazenamento ao longo do tempo. Observase que, de maneira geral, as médias no primeiro e no terceiro mês foram superiores, comparadas às do sexto e do nono meses, para ambas as condições de armazenamento (AN e CC), mas somente no sexto mês de armazenamento houve diferença entre as condições cujas sementes armazenadas na CC apresentaram maior porcentagem de PJN comparadas a AN (média de 78,1 e 72,1 , respectivamente) sendo uma diferença de $6 \%$ nas médias. Esses resultados possivelmente podem ser devidos ao teor de água das sementes neste mês, que no AN apresentava valores médios inferiores $(6,3 \%)$ ao recomendado para o armazenamento seguro das sementes de soja (12\%) demonstrando, desta forma, que em

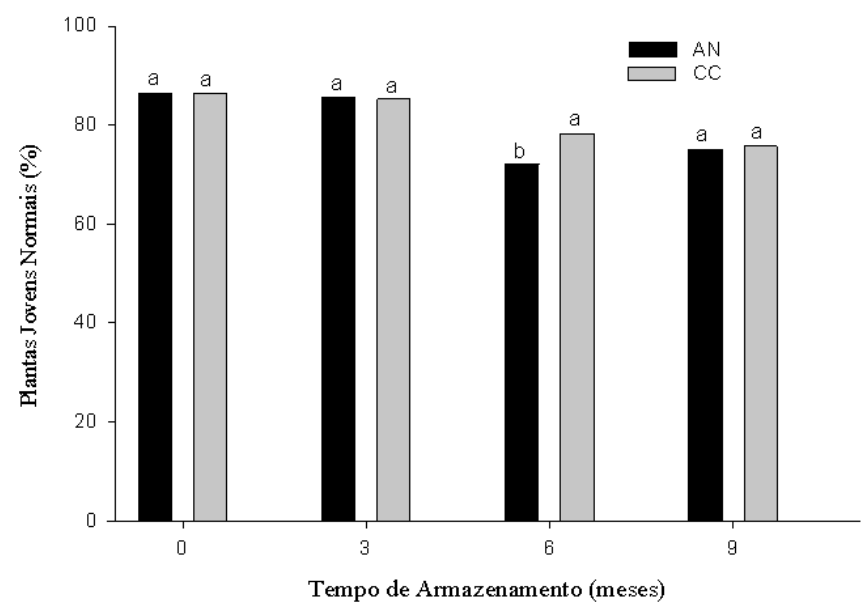

Figura 6. Plantas jovens normais (\%) emergidas em areia das sementes de soja nas condições de armazenamento em ambiente natural - AN e câmara climatizada - CC ao longo do tempo de armazenamento

ambas as condições houve perda do vigor ao longo do tempo de armazenamento. Cunha et al. (2009) citam que a deterioração pode se intensificar com o prolongamento do período de armazenamento mesmo em ambiente refrigerado, prejudicando $o$ vigor das sementes armazenadas.

\section{Conclusões}

1. Houve diferenças entre as etapas do beneficiamento (danos mecânicos no mês inicial, vigor e CR), mas na maioria dos casos não interferiu na qualidade fisiológica das sementes.

2. Quanto ao padrão mínimo de germinação exigido pelo Ministério da Agricultura para comercialização de semente (> 80\%), as sementes da cultivar de soja BMX Potência RR, apresentam características superiores pelo teste de tetrazólio com a maioria dos valores de danos mecânicos (nível 6-8) inferiores a 3,0 e vigor (nível 1-3) acima de 88,0\%.

3. Apesar do vigor, germinação e emergência se terem mantido altos durante nove meses de armazenamento, a comprimento da raiz e as plantas jovens normais são influenciadas negativamente pelo tempo principalmente em ambiente natural.

4. Em câmara climatizada as sementes apresentam melhor conservação comparativamente ao ambiente natural.

\section{Agradecimentos}

Ao CNPq, Sementes Goiás, CAPES, Instituto Federal Goiano e FINEP.

\section{Literatura Citada}

Azevedo, M. R. Q. de A.; Gouveia, J. P. G. de; Trovão, D. M. M.; Queiroga, V. de P. Influência das embalagens e condições de armazenamento no vigor de sementes de gergelim. Revista Brasileira de Engenharia Agrícola e Ambiental, v.7, p.519524, 2003 
Baudet, L. M. L.; Villela, F. A.; Cavariani, C. Princípios de secagem. Seed News, s/v, p.20-27, 1999.

Bezerra, A. M. E.;Medeiros Filho, S.; Freitas, J.B.S.F.; Teófilo, E.M. Avaliação da qualidade das sementes de Moringa oleífera Lam. durante o armazenamento. Ciência e Agrotecnologia, v.28, p.1240-1246, 2004.

Brasil. Ministério da Agricultura, Pecuária e Abastecimento. Secretaria de Defesa Agropecuária. Regras para análise de sementes. Brasília: Mapa/ACS, 2009. 395p.

Carvalho, N. M.; Nakagawa, J. Sementes: Ciência, tecnologia e produção. 5.ed. Jaboticabal: FUNEP, 2012. 590p

Cunha, J. P. A. R.; Oliveira, P.; Santos, C. M.; Mion, R. L. Qualidade das sementes de soja após a colheita com dois tipos de colhedora e dois períodos de armazenamento. Ciência Rural, v.39, p.1420-1425, 2009.

Dan, L. G. M.; Dan, H. A.; Barroso, A. L. L.; Braccini, A. L. Qualidade fisiológica de sementes de soja tratadas com inseticidas sob efeito do armazenamento. Revista Brasileira de Sementes, v.32, p.131-139, 2010.

Dan, L. G. M.; Dan, H .A.; Braccini, A. L.; Albrecht, L. P.; Ricci, T. T.; Piccinin, G. G. Desempenho de sementes de soja tratadas com inseticidas e submetidas a diferentes períodos de armazenamento. Revista Brasileira de Ciências Agrárias, v.6, p.215-222, 2011.

Ferreira, R. L.; Sá, M.E. Contribuição de etapas do beneficiamento na qualidade fisiológica de sementes de dois híbridos de milho. Revista Brasileira de Sementes, v.32, p.099-110, 2010.

França Neto, J. B. (ed.). Vigor de sementes: Conceitos e testes. Londrina: ABRATES, 1999. Cap. 8, p.5-28.

Kolchinski, E. M.; Schuch, L. O. B.; Peske, S. T. Vigor de sementes e competição intra- específica em soja. Ciência Rural, v.35, p.1248- 1256, 2005.

Kryzanowski, F. C.; Henning, A. A.; França Neto, J. B.; Costa, N. P. Tecnologias que valorizam a semente de soja. Seed News, p.24-27, 2006.

Lopes, M. M.; Prado, M. O. D.; Sader, R.; Barbosa, R. M. Efeitos dos danos mecânicos e fisiológicos na colheita e beneficiamento de sementes de soja.Bioscience Journal, v.27, p.230-238, 2011.

Macedo, E.; Groth, D.; Soave, J. Influência da embalagem e do armazenamento na qualidade fisiológica de sementes de algodão. Revista Brasileira de Sementes, v.20, p.454-461, 1998.
Maguire, J. D. Speed of germination aid in selection and evaluation for seedling emergence and vigor. Crop Science, v.2, p.176-177, 1962.

Marcos Filho, J. Deterioração de sementes. In: Marcos Filho, J. (ed.). Fisiologia de sementes de plantas cultivadas. Piracicaba: FEALQ, 2005. Cap.9, p.291-348.

Marcos Filho, J. Importância do potencial fisiológico da semente de soja. Informativo ABRATES, v.23, p.21-23, 2013.

Nakagawa, J. Testes de vigor baseados no desempenho das plântulas. In: krzyzanowski, F. C.; Vieira, R. D.; França Neto, J. B. (ed). Vigor de sementes: Conceitos e testes. Londrina: ABRATES. p.2.1-2.24, 1999.

Oliveira, A.; Sader, R.; Krzyzanowski, F. C. Danos mecânicos ocorridos no beneficiamento de sementes de soja e suas relações com a qualidade fisiológica. Revista Brasileira de Sementes, v.21, p.59-66, 1999.

Salinas, A. R.; Yoldjian, A. M.; Craviotto, R. M.; Bisaro, V. Pruebas de vigor y calidad fisiológica de semillas de soja. Pesquisa Agropecuária Brasileira, v.36, p.371379, 2001.

Scheeren, B. R.; Peske, S. T.; Schuch, L. O. B.; Barros, A. C. A. Qualidade fisiológica e produtividade de sementes de soja. Revista Brasileira de Sementes, v.32, p.35-41, 2010.

Silva, J. B. da; Lazarini, E.; Sá, M. E. de. Comportamento de sementes de cultivares de soja, submetidos a diferentes períodos de envelhecimento acelerado. Bioscience Journal, v.26, p.755-762, 2010.

Silva, R. P.; Teixeira, I. R.; Devilla, I. A.; Rezende, R. C.; Gisele Silva, G. C. Qualidade fisiológica de sementes de soja (Glycinemax L.) durante o beneficiamento. Semina: Ciências Agrárias, v.32, p.1219-1230, 2011.

Tunes, L. M.; Pedroso, D. C.; Badinelli, P. G.; Tavares, L. C.; Rufino, C. A.; Barros, A. C. S. A.; Muniz, M. F. B.Envelhecimento acelerado em sementes de azevém com esem solução salina e saturada. Ciência Rural, v.41, p.3337, 2011.

Vanzolini, S.; Araki, C. A. S.; Silva, A. C. T. M.; Nakagawa, J. Teste de comprimento de plântula na avaliação da qualidade fisiológica de sementes de soja. Revista Brasileira de Sementes,v.29, p.90-96, 2007. 